\title{
Aqueous two-phase micellar systems in an oscillatory flow micro-reactor: study of perspectives and experimental performance
}

\author{
André M. Lopes, ${ }^{a, b}$ Daniel P. Silva, ${ }^{a, c *}$ António A. Vicente, ${ }^{a}$ \\ Adalberto Pessoa-Jrb and José A. Teixeira ${ }^{a}$
}

\begin{abstract}
BACKGROUND: Aqueous two-phase micellar systems (ATPMS) are micellar surfactant solutions with physical properties that make them very efficient for the extraction/concentration of biological products. In this work the main proposal that has been discussed is the possible applicability and importance of a novel oscillatory flow micro-reactor (micro-OFR) envisaged for parallel screening and/or development of industrial bioprocesses in ATPMS. Based on the technology of oscillatory flow mixing (OFM), this batch or continuous micro-reactor has been presented as a new small-scale alternative for biological or physical-chemical applications.

RESULTS: ATPMS experiments were carried out in different OFM conditions (times, temperatures, oscillation frequencies and amplitudes) for the extraction of glucose-6-phosphate dehydrogenase (G6PD) in Triton X-114/buffer with Cibacron Blue as affinity ligand.

CONCLUSION: The results suggest the potential use of OFR, considering this process a promising and new alternative for the purification or pre-concentration of bioproducts. Despite the applied homogenization and extraction conditions have presented no improvements in the partitioning selectivity of the target enzyme, when at rest temperature they have influenced the partitioning behavior in Triton X-114 ATPMS.

(c) 2011 Society of Chemical Industry
\end{abstract}

Keywords: screening micro-reactor; oscillatory flow mixing; aqueous two-phase micellar system; triton X-114; affinity ligand; glucose6-phosphate dehydrogenase

\section{INTRODUCTION}

Bioseparation can be defined as the set of sequential unit operations which, in a bioprocess, result in the recovery and purification of biological products. ${ }^{1}$ Recently several optimizations for bioseparation processes have been reported..$^{2-4}$ In this context, liquid-liquid extraction, a process based on partition of proteins, enzymes or any other bioproduct of interest between two liquid phases, has been successfully carried out at a large scale for more than a decade. Moreover, this process has important intrinsic advantages, such as efficiency, versatility and low cost, as well as biocompatibility and the fact that it can be easily scaled up to the industrial level. ${ }^{2}$

Among the several liquid-liquid extraction techniques, aqueous two-phase micellar systems (ATPMS) formed by some surfactants at specific conditions have attracted considerable attention in recent years. In ATPMS, an aqueous surfactant solution, under appropriate conditions, spontaneously separates into two predominantly aqueous, yet immiscible, liquid phases, one of which has a greater concentration of micelles than the other. In these systems, in particular, differences between the physicochemical environments in the micelle-rich phase and in the micelle-poor phase allow an attractive and effective option for extraction processes. ${ }^{5,6}$ Thus, ATPMS offer both hydrophobic and hydrophilic environments, providing selectivity to the molecule partitioning according to its hydrophobicity. These systems have been evaluated for the extraction and purification of proteins, ${ }^{7,8}$ viruses, ${ }^{5}$ enzymes, ${ }^{9,10}$ antibiotics, ${ }^{6}$ DNA and nucleic acids, ${ }^{11}$ optimized membrane solubilization, ${ }^{12}$ and partitioning of tagged and genetically engineered proteins. ${ }^{13}$ This possible attainment of pre-concentration using phase separation by surfactant-based techniques provides a convenient alternative to the more conventional extraction schemes.

On the one hand, the development of new techniques or procedures for the separation and purification of enzymes has

\footnotetext{
* Correspondence to: DanielP. Silva, Instituto de Tecnologia e Pesquisa - ITP/UNIT, Universidade Tiradentes, Campus Farolândia, Av. Murilo Dantas, 300 Bairro Farolândia 49032-490, Aracaju, Sergipe, Brasil. E-mail: silvadp@hotmail.com

a IBB - Institute for Biotechnology and Bioengineering, Centre of Biological Engineering, University of Minho, Campus de Gualtar, Braga, 4710-057, Portugal

b Dept of Biochemical-Pharmaceutical Technology, School of Pharmaceutical Sciences, University of São Paulo, São Paulo, 05508-900, Brazil

c Instituto de Tecnologia e Pesquisa, Universidade Tiradentes, Campus Farolandia, Aracaju-Sergipe, 49032-490, Brazil
} 


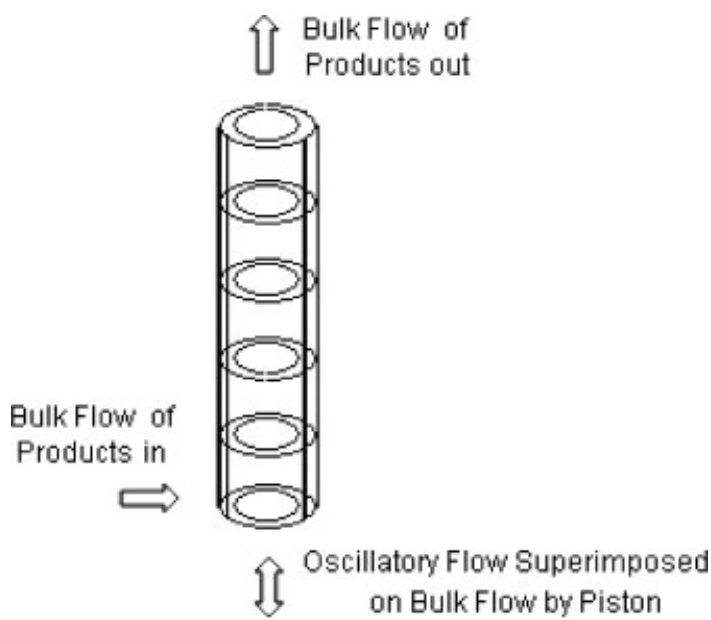

Figure 1. Oscillatory flow reactor adapted from Harvey et al..$^{38}$

been an indispensable prerequisite for many of the advancements in the biotechnological industry, especially with the increasing interest in biofuels. The application of these liquid-liquid extraction processes implies the consideration of using continuous operations at the stage of process design, which could reduce fixed and variable costs, and increase space-time yield. . $^{314,15}$ Otherwise, a number of recent studies also concentrate on developing small-scale systems to support the actual high demand of highthroughput screening experiments.

These studies based on experimental observation made in the late 1980s, aiming at generating unsteadiness in a laminar flow showed that when a periodically reversing flow exists in a tube fitted with orifice-type baffles mounted transverse to the flow and equally spaced, vortex rings are formed downstream of the baffles. The flow visualization clearly showed that large-scale eddy mixing can be generated in regions between sharp edges with efficient radial and axial eddy mixing. ${ }^{16,17}$

The application of periodic fluid oscillations to a cylindrical column containing evenly spaced orifice baffles is the basic concept of an oscillatory flow reactor (OFR), as shown in Fig. 1. The OFR can be operated batch wise or continuously in horizontal or vertical tubes. The liquid or multiphase fluid is typically oscillated in the axial direction by means of diaphragms, bellows or pistons, at one or both ends of the tube, developing an efficient mixing mechanism (oscillatory flow mixing) where fluid moves from the walls to the centre of the tube with intensity controlled by the oscillation frequency and amplitude. ${ }^{16,18-20}$ In recent years, the study of OFM within OFRs has increasingly been applied to various industrial processes, such as suspension polymerization, crystallization, paint dispersion, flocculation and fermentation. ${ }^{21-23}$

In this work the experimental performance of a novel microreactor with possibilities of application as screening tool, operated under oscillatory flow mixing (OFM), has been tested in liquid-liquid extraction ATPMS. In spite of recent efforts in liquid-liquid extraction studies, to our knowledge there is no evaluation of oscillatory flow mixing applied to biomolecules recovery reported in the literature. This work discusses the influence of different homogenization conditions (time, temperature, frequency, and amplitude) on the extraction performance and partitioning behavior in ATPMS. An additional objective was to investigate the effect of different rest temperatures on the partition coefficients. In most of the experiments a comparison was made between the two different processes of homogenization considered: oscillatory flow mixing and simple rotation.

In this context, glucose-6-phosphate dehydrogenase (G6PD), a dimer with a total molecular weight of $103700 \mathrm{~g} \mathrm{~mol}^{-1}$ and with an isoelectric point of 4.6, was used as biomolecule target. This enzyme catalyses the first step of the pentose phosphate pathway, and was chosen because of its numerous applications in medical and biochemical studies. ${ }^{24,25}$ Besides, in Brazil, the use of Saccharomyces cerevisiae as a source of this enzyme and other products is sensible owing to a wide experience in handling this strain in industrial plants. Thus, coupling yeast processing (e.g. for the production of intra-cellular enzymes) with the bioethanol production processes should have a positive effect on the profits of the distilleries. ${ }^{26,27}$

\section{MATERIALS AND METHODS}

\section{Chemicals and materials}

The nonionic surfactant octylphenol ethoxylate (Triton X-114) and Cibacron Blue 3 GA (affinity ligand) were used in the preparation of the systems, while glucose-6-phospate dehydrogenase (EC 1.1.1.49) from Leutonostoc mesenteroids was used as target enzyme in the partitioning experiments. $\beta$-nicotinamide adenine dinucleotide phosphate $\left(\beta-\mathrm{NADP}^{+}\right)$and glucose-6-phosphate (G6P) were used in the enzymatic analyses. All these products were obtained from Sigma Chemical Company (St Louis, USA). The other reagents were of analytical or reagent grade.

The solutions were prepared in Mcllvaine's buffer, $\mathrm{pH} 7.2$, consisting of $16.4 \mathrm{mmol} \mathrm{L}^{-1}$ disodium phosphate and $1.82 \mathrm{mmol} \mathrm{L}^{-1}$ citric acid in water purified through a Millipore Milli-Q ionexchange system (Bedford, MA). The glassware used was washed in a $50: 50$ ethanol: $1 \mathrm{~mol} \mathrm{~L}^{-1}$ sodium hydroxide solution, followed by $1 \mathrm{~mol} \mathrm{~L}^{-1}$ nitric acid, rinsed several times with Milli-Q water, and finally dried in an oven, eliminating possible contaminations or effects caused by detergent residues.

\section{Oscillatory flow micro-reactor (micro-OFR): geometry and operation}

The oscillatory flow micro-reactor system is formed by several jacketed glass tubes of $4.4 \mathrm{~mm}$ internal diameter and $35 \mathrm{~cm}$ length. Each tube has a volume of $c a 4.5 \mathrm{~mL}$ and is provided with smooth periodic constrictions (SPC), as shown in Fig. 2(A) and 2(B).

Oscillatory flow conditions were provided by a rotative ceramic piston pump (CKCRH0, Fluid Metering Inc., New York, USA), working in closed-loop connected to the bottom of the microreactor. The control of oscillation amplitude was possible by turning an easy-grip flow control ring in the pump head, in a range from 0 to $3.0 \mathrm{~mm}$ (centre-to-peak), while the oscillation frequencies were focused in the range 0 to $25.5 \mathrm{~s}^{-1}$, controlled by the rotation speed of the ceramic piston. The temperature was controlled by circulating water at the desired temperature through the jacket of the SPC tube.

In most experiments a comparison was made between two different processes of homogenization: oscillatory flow mixing (Fig. 2(A) and 2(B)) and simple rotation as shown in Fig. 2(C) (Stuart Rotator mod. SB3). The typical profile of the oscillations obtained in the micro-OFR is show in Fig. 3.

\section{Mapping the phase diagram of the Triton X-114/buffer systems: Binodal curve}

The phase diagram of the nonionic surfactant Triton X-114 in buffer was obtained by the cloud-point method. ${ }^{28-30}$ Briefly, buffered 


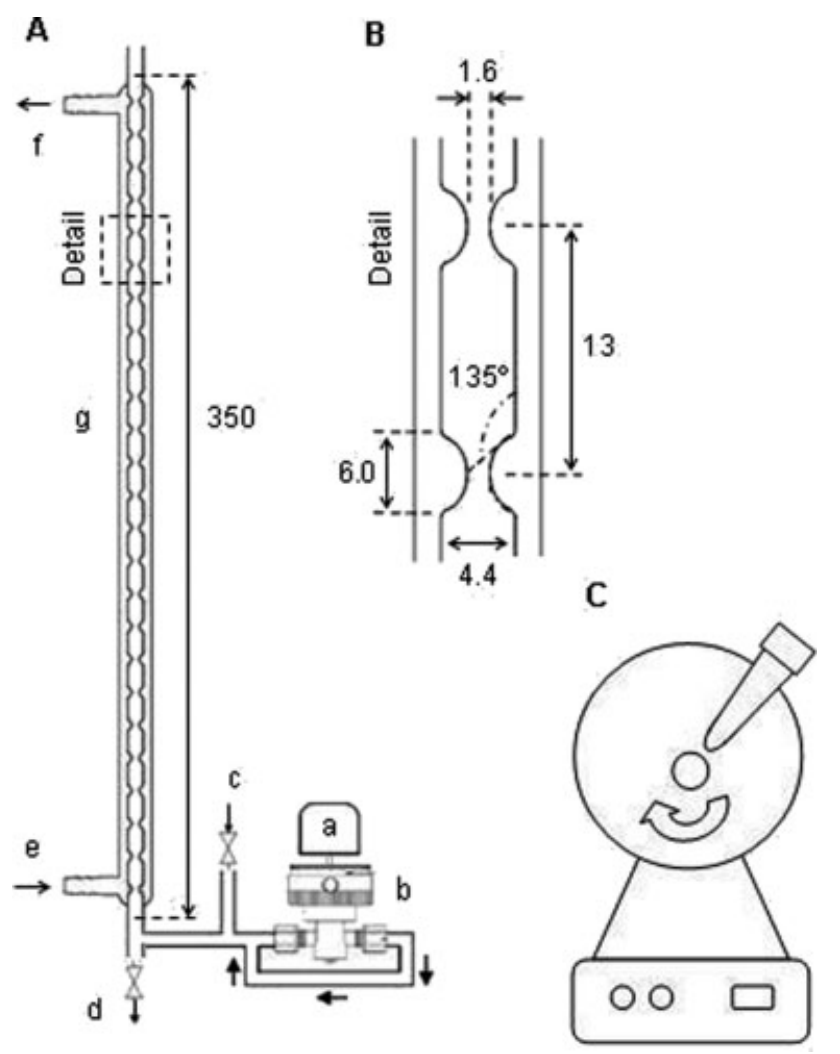

Figure 2. (A) Experimental apparatus of an oscillatory flow micro-reactor: a. agitator, b. piston pump, c. reagents inlet, d. sampling port, e. temperature control inlet, f. temperature control outlet, g. SPC tube. (B) Detail of the SPC (smooth periodic constriction) tube geometry, which forms the novel oscillatory flow micro-reactor (dimensions in $\mathrm{mm}$ ). (C) Experimental apparatus of a traditional rotation system.

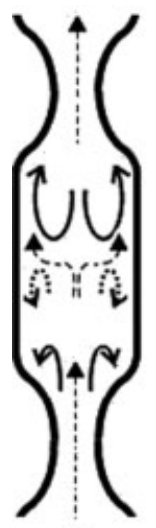

(a)

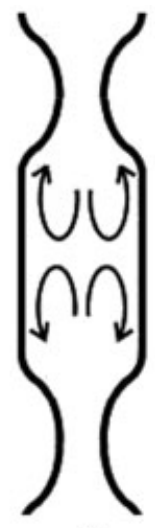

(b)

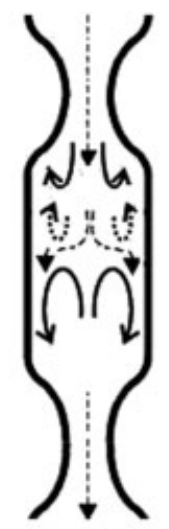

(c)

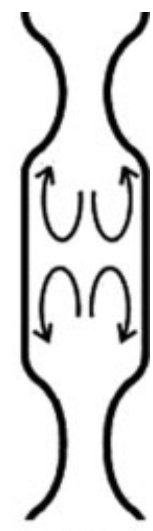

(d)
Figure 3. Typical profile of oscillations obtained in the micro-OFR; the dashed arrows represent vortex ring positions while dotted arrows represent locations of main fluid net stream: (a) half-way upstroke; (b) flow reversal; (c) half-way downstroke; and (d) flow reversal. Adapted from Reis et al. ${ }^{32,39}$

surfactant solutions of known concentrations were prepared and placed in a transparent thermo-regulated device. A magnetic stirrer was used to ensure temperature and concentration homogeneity. The temperature was first lowered such that the solution exhibited a single and clear phase. Then, the temperature was raised slowly, and the temperature at which the solution first became cloudy indicated the onset of phase separation. The Triton X-114 concentration in each coexisting phase of a twophase system can be read off the phase diagram by noting the intersections of the operating tie-line and the fitted phase diagram. The procedure was repeated three times for each data point to ensure reproducibility.

Aqueous two-phase micellar systems (ATPMS): composition and preparation

ATPMS were prepared in graduated centrifuge tubes $(15 \mathrm{~mL})$ by addition of the desired amounts of surfactant TX-114 (3\% wt/wt), Cibacron Blue ( $0.005 \mathrm{mg} \mathrm{g}^{-1}$ ) and G6PD in Mcllvaine buffer. Deionized water was then added to the mixture in order to adjust the final concentration of the components to the desired levels, whereas the $\mathrm{pH}$ values of the systems in the experiments were the same as those of the buffer solution.

The total masses used in the ATPMS were 3.2 and $7.2 \mathrm{~g}$ when at oscillatory flow in the micro-reactor and traditional rotation system, respectively. Since the enzymatic assay for determination of G6PD concentrations is very sensitive, there was no need to use large amounts of the enzyme, and therefore, the overall G6PD concentration in each partitioning experiment was $0.0068 \mathrm{wt} \%$ $\left(0.7 \mathrm{mmol} \mathrm{L}^{-1}\right)$. The resulting solutions were used in the different studies. At least two reproducible replicates were obtained for each experiment.

\section{Effect of homogenization method on ATPMS}

The effect of different methods of homogenization on the formation and equilibrium of ATPMS was first evaluated without addition of the target enzyme (G6PD). Systems with and without Cibacron Blue as affinity ligand were homogenized by simple rotation at $8 \mathrm{rpm}$ or by oscillatory flow mixing at $25.5 \mathrm{~s}^{-1}$ frequency and $3.0 \mathrm{~mm}$ amplitude, for $15 \mathrm{~min}$ at $25^{\circ} \mathrm{C}$. Subsequently, the solutions were placed in a thermo-regulated device, previously set at $29^{\circ} \mathrm{C}$ and maintained for $120 \mathrm{~min}$ to attain partitioning equilibrium. After partitioning equilibrium was attained (twophase formation), the volume of the micellar phases were measured, and in systems with affinity ligand a small sample fraction $(0.3 \mathrm{~mL})$ was withdrawn from each phase with great care using a syringe, for the determination of ligand concentration.

\section{Effect of the time and temperature of homogenization on partition coefficients}

In this task, initially the influence of homogenization time (5, 10, and $15 \mathrm{~min}$ ) on the G6PD partition coefficient was evaluated using ATPMS without affinity ligand. Subsequently, the effects of homogenization time (15 and $45 \mathrm{~min}$ ) together with homogenization temperature $\left(25\right.$ and $\left.45^{\circ} \mathrm{C}\right)$ were evaluated on G6PD and affinity ligand partition coefficients. The systems were again homogenized by simple rotation $(8 \mathrm{rpm})$ and by oscillatory flow mixing $\left(25.5 \mathrm{~s}^{-1} / 3.0 \mathrm{~mm}\right)$ for the desired times and temperatures. In the sequence, the solutions were placed under the same rest conditions previously described $\left(30^{\circ} \mathrm{C} / 120 \mathrm{~min}\right)$. Immediately after this procedure the volumes of the phases were measured and samples withdrawn for analysis.

\section{Effect of oscillatory flow mixing conditions on the partition coefficients}

In other partitioning experiments, the effects of different homogenization conditions on the partition coefficient were evaluated 
for different oscillatory flow mixing settings: $25.5,12.5$, and $2 \mathrm{~s}^{-1}$ frequency maintaining the amplitude at 3.0; and then 3.0, 1.5, and $0.5 \mathrm{~mm}$ amplitude maintaining the frequency at $12 \mathrm{~s}^{-1}$. After this procedure, the systems were treated under the same rest conditions previously described $\left(30^{\circ} \mathrm{C} / 120 \mathrm{~min}\right)$ with subsequent samples withdrawn for analysis.

\section{Effect of rest temperature on the partition coefficients}

After ensuring partition equilibrium through the different homogenization processes (simple rotation and oscillatory flow mixing), the effect of rest temperature on the partition coefficients was evaluated in each experiment for different conditions: 27,29 , and $32^{\circ} \mathrm{C}$. Immediately after this procedure samples were withdrawn for analysis.

\section{Analytical methodology}

The determination of G6PD concentrations in the aqueous solutions or phases obtained (with or without surfactant agent) was based on a well established enzymatic assay, ${ }^{24}$ with some minor alterations because of the conditions of the partition experiments. In this way, to prevent phase turbidity/separation during the assay, all enzymatic assays were carried out in Mcllvaine buffer (instead of Tris- $\mathrm{HCl}$ ), and at a control temperature at $15^{\circ} \mathrm{C}$ (instead at $37^{\circ} \mathrm{C}$ ). The G6PD activity was measured spectrophotometrically (Jasco, model V-560) by determining the rate of NADPH formation in a coupled enzyme assay system, which absorbs ultraviolet light at $340 \mathrm{~nm}$. One unit (U) of enzyme activity was defined as the amount of enzyme that catalyzes the reduction of $1 \mu \mathrm{mol}$ of $\mathrm{NADP}^{+}$per minute under the experimental conditions employed. The assay mixture consisted of $600 \mu \mathrm{L}$ Mcllvaine buffer (pH 7.2), $15 \mu \mathrm{L}$ glucose 6-phosphate $250 \mathrm{mmol} \mathrm{L}^{-1}, 5 \mu \mathrm{LNADP}^{+} 131 \mathrm{mmol} \mathrm{L}^{-1}$ and $20 \mu \mathrm{L}$ sample containing the enzyme. The partition coefficient of the enzyme $\left(K_{\mathrm{G} 6 \mathrm{PD}}\right)$ was defined as the ratio between the enzyme activities in the micelle-rich phase and the micelle-poor phase. The extraction yield was obtained from the ratio between the total activity of the enzyme in the phases obtained after and before the extraction, using the volume of each phase.

The ligand concentrations (Cibacron Blue) in the phases were also measured spectrophotometrically. For this, a scan of the visible spectrum was evaluated to find the absorbance peak of the affinity ligand used $(\lambda=611 \mathrm{~nm})$, and calibration curves were prepared. In the assays, the interference of the surfactant solution was considered by use of one blank sample. The partition coefficient of the affinity ligand $\left(K_{\mathrm{AL}}\right)$ was defined as the ratio between the ligand concentration in the micelle-rich phase and in the micelle-poor phase. All these determinations were repeated at least two times to ensure reproducibility.

\section{RESULTS AND DISCUSSION}

\section{Binodal curve}

In the study and development of liquid-liquid extraction processes the first step is to obtain the phase diagram for the type of system chosen. This phase diagram (or binodal curve) would represent the boundary separating the one-phase region from the two-phase region, providing the volumetric ratio between the respective phases at different conditions. In this work, the phase diagram of the TX-114/buffer micellar system was obtained to evaluate the best surfactant concentration and temperature for two-phase formation in the range of operating conditions studied, as shown in Fig. 4.

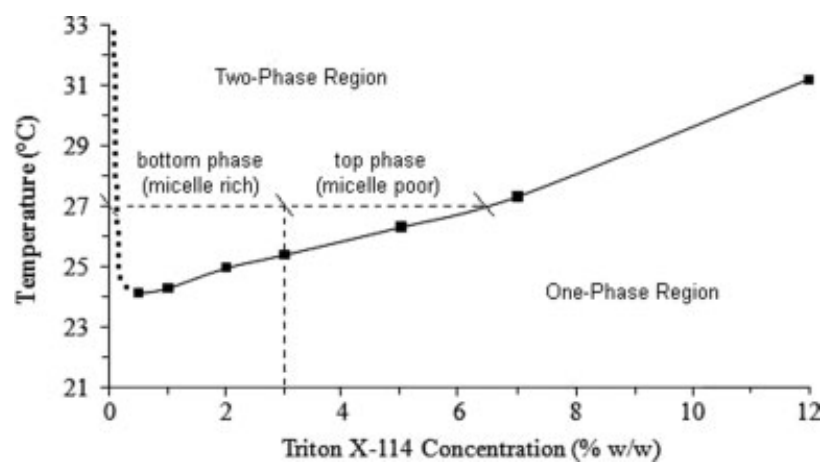

Figure 4. Experimentally determined phase diagram of the TX-114/buffer micellar system, showing the two-phase and one-phase regions. The corresponding volumetric ratio between the phases in 3\% wt/wt Triton $\mathrm{X}-114$ and $27^{\circ} \mathrm{C}$ temperature is also indicated.

Table 1. Effect of different homogenization systems (simple rotation, $8 \mathrm{rpm} / 15 \mathrm{~min}$, or oscillatory flow mixing, $25.5 \mathrm{~s}^{-1} / 3.0 \mathrm{~mm} / 15 \mathrm{~min}$ ) on the volumetric ratio of the phases $\left(V_{R}\right)$ and on the partition coefficient of the affinity ligand $\left(K_{A L}\right)$ in $3 \%$ wt/wt TX-114/buffer ATPMS $\left(25^{\circ} \mathrm{C}\right)$, without (run 1 and 2) or with (run 3 and 4) affinity ligand, after resting at $29^{\circ} \mathrm{C}$ during $120 \mathrm{~min}$

\begin{tabular}{llcc|} 
Experiment & $\begin{array}{c}\text { Homogenization } \\
\text { system }\end{array}$ & $V_{R}$ & $K_{A L}$ \\
\hline 1 & rotation & $0.25 \pm 0.03$ & - \\
2 & oscillatory & $0.27 \pm 0.04$ & - \\
3 & rotation & $0.40 \pm 0.03$ & $10.5 \pm 1.1$ \\
4 & oscillatory & $0.41 \pm 0.03$ & $11.2 \pm 1.8$ \\
\hline
\end{tabular}

The curve showed a significant variation as a function of both variables evaluated (surfactant concentration and temperature). In aqueous solutions of the nonionic surfactant Triton X114 macroscopic phase separation occurs upon increasing the temperature over a temperature known as the cloud-point of the surfactant, resulting in a bottom micelle-rich phase, and a top micelle-poor phase. ${ }^{31}$

Thus, aiming to obtain a significant volume range between phases, the systems at 3.0\% wt/wt of surfactant concentration and rest temperatures above $27^{\circ} \mathrm{C}$ were chosen as initial conditions for subsequent experiments.

\section{Experimental performance of the micro-OFR in ATPMS}

In previous studies using the same micro-OFR applied in this work, the flow patterns within each SPC-tube as well as their advantages for fast development of industrial bioprocesses were demonstrated. ${ }^{32,33}$ These authors have shown high radial rates of flow exchange between the walls and the centre of the tube during the complete oscillation cycle, coupled with high velocity gradients, as illustrated in Fig. 3.

In the present work, different mixture conditions (homogenization profiles) obtained with the micro-OFR were established to verify similar or better performance of the extraction process in ATPMS when compared with the conventional means of agitation. However, before proceeding with the partitioning experiments using the G6PD enzyme as biomolecule-target for extraction, ATPMS were prepared and conducted to initially evaluate possible interference in the formation of two-phase systems, as shown in Table 1. 
Table 2. Effect of different times and systems of homogenization (simple rotation, $8 \mathrm{rpm}$, or oscillatory flow mixing, $25.5 \mathrm{~s}^{-1} / 3.0 \mathrm{~mm}$ ) on the volumetric ratio of the phases $\left(V_{R}\right)$ and on the partition coefficient of the G6PD ( $\left.K_{\mathrm{G} 6 \mathrm{PD}}\right)$ in $3 \% \mathrm{wt} / \mathrm{wt}$ Triton X-114/buffer ATPMS $\left(25^{\circ} \mathrm{C}\right)$, without affinity ligand, after resting at $30^{\circ} \mathrm{C}$ for $120 \mathrm{~min}$

\begin{tabular}{|c|c|c|c|c|}
\hline \multirow[b]{2}{*}{ Experiment } & \multicolumn{2}{|c|}{ Homogenization } & \multirow[b]{2}{*}{$V_{R}$} & \multirow[b]{2}{*}{$K_{\mathrm{G} 6 \mathrm{PD}}$} \\
\hline & System & Time (min) & & \\
\hline 1 & rotation & 5 & $0.36 \pm 0.03$ & $0.33 \pm 0.03$ \\
\hline 2 & oscillatory & 5 & $0.38 \pm 0.02$ & $0.38 \pm 0.03$ \\
\hline 3 & rotation & 10 & $0.41 \pm 0.03$ & $0.35 \pm 0.04$ \\
\hline 4 & oscillatory & 10 & $0.40 \pm 0.02$ & $0.37 \pm 0.02$ \\
\hline 5 & rotation & 15 & $0.43 \pm 0.01$ & $0.36 \pm 0.03$ \\
\hline 6 & oscillatory & 15 & $0.45 \pm 0.02$ & $0.36 \pm 0.03$ \\
\hline
\end{tabular}

According to the results (experiments $1-2$ and $3-4$, Table 1 ) no modification or interference was observed on the characteristics of formation of two-phase systems, on the values of the volumetric ratio of the micellar phases $\left(V_{R}\right)$, or on the partition coefficients of the affinity ligand $\left(K_{A L}\right)$, when comparing the results obtained with oscillatory flow mixing (micro-OFR) with those using a conventional rotation process (traditional agitation). The observed volumetric ratios without the affinity ligand were approximately 0.3 ( $3 \% \mathrm{wt} /$ wt Triton X-114/buffer system, rest at $30^{\circ} \mathrm{C} / 120 \mathrm{~min}$ ), which also confirmed the accuracy of the measured phase diagram (Fig. 4), since for this surfactant concentration and temperature this relationship was observed.

After this initial conclusion, it was possible to proceed with the partitioning experiments adding the G6PD. All these experiments showed average mass balance values of $95 \pm 15 \%$ and were conducted for the two different homogenization methods for comparison: simple rotation and oscillatory flow mixing.

Table 2 presents the results of partitioning experiments used to evaluate the effect of the homogenization time on the volumetric ratio of the phases $\left(V_{R}\right)$ and on the G6PD partition coefficient $\left(K_{\mathrm{G} 6 \mathrm{PD}}\right)$ in ATPMS (3\% wt/wt TX-114/buffer, $\left.25^{\circ} \mathrm{C}\right)$, after resting at $30^{\circ} \mathrm{C} / 120 \mathrm{~min}$. As can be seen, most of the values obtained are similar, with a probable loss or decrease in $K_{\mathrm{G} 6 \mathrm{PD}}$ when short homogenization times were used together with simple rotation (e.g. $5 \mathrm{~min}$ ). These results indicate that for rapid homogenization processes, oscillatory flow mixing seems to be more efficient. That can be explained by the complexity of the fluid flow patterns in oscillatory systems, which lead to faster and better homogenization.

In the literature, the use of Triton X-114 ATPMS for the purification of $S$. cerevisiae cell homogenate was found to be efficient in the recovery of G6PD in the dilute micelle-poor phase, partially separating this target molecule from other proteins and contaminants of hydrophobic character. Therefore, these systems can be considered useful as a possible purification stage in a biotechnological process. In this work, pure G6PD from Sigma was used to evaluate the performance of a novel methodology for the homogenization in liquid-liquid extraction, with improved possibilities of process control. As observed in Table 2, the excluded-volume effect was dominant in all the systems studied and, therefore, the enzyme G6PD partitioned preferentially to dilute and micelle-poor phase, in which there is a higher volume available, resulting in $K_{\mathrm{G} 6 \mathrm{PD}}$ values lower than one unit.

However, the use of affinity interactions has been suggested as a new method to improve the yield and the specificity in liquid-liquid extraction processes. ${ }^{34,35} \mathrm{~A}$ particularly attractive feature of these systems is the prospect of being able to select a target protein by preferentially extracting it into the micelle-rich phase, while simultaneously removing most of the contaminants into the micelle-poor phase. ${ }^{8}$ Aqueous two-phase micellar systems may be a more convenient choice in affinity-enhanced extractions than their polymer counterparts, because the ligands might be incorporated in situ by micellar self-assembly, thus eliminating the need for time-consuming and expensive chemical synthesis. Nevertheless, there have been relatively few attempts to apply the concept of free affinity ligands to carry out bioseparations in two-phase aqueous micellar systems. ${ }^{2}$

The triazine dye Cibacron Blue $3 \mathrm{GA}$ has been studied as affinity ligand for G6PD purification using chromatography by other authors. ${ }^{36,37}$ In spite of the clear presence of affinity interactions, we have presented experimental results regarding the role of affinity interactions on the partitioning of the hydrophilic enzyme G6PD in ATPMS composed of the surfactants Triton X-114 and $\mathrm{C}_{10} \mathrm{E}_{4} \cdot{ }^{10}$ According to the results such interactions were not strong enough to significantly overcome the excluded-volume effect and drive the enzyme preferentially to the micelle-rich phase containing the affinity ligand.

Thus, the combined effects of time and temperature during the homogenization process on extraction behavior in ATPMS were also studied using the affinity ligand in the extraction systems. Under these conditions, no alteration was observed in the partition values (Table 3). Moreover, under the conditions evaluated the use of the affinity ligand in G6PD partitioning systems (Triton X-114) did not promote an increase of $K_{\mathrm{G} 6 \mathrm{PD}}$, which was kept at values lower than unity.

In the subsequent extraction experiments several were conducted to evaluate the effects of different frequencies and amplitudes (variables in oscillatory flow mixing) on the G6PD and affinity ligand partition coefficients $\left(K_{\mathrm{G} 6 \mathrm{PD}}\right.$ and $K_{A L}$, respectively) using a homogenization time of $15 \mathrm{~min}$ at a temperature at $25^{\circ} \mathrm{C}$. However, the conditions applied during this work were not

Table 3. Effect of different times and temperatures of homogenization at oscillatory flow mixing $\left(12.5 \mathrm{~s}^{-1} / 1.5 \mathrm{~mm}\right)$ on the volumetric ratio of the phases $\left(V_{R}\right)$, and on the partition coefficients of G6PD and of the affinity ligand ( $K_{\mathrm{G} 6 \mathrm{PD}}$ and $K_{\mathrm{AL}}$, respectively) in $3 \%$ wt/wt Triton X-114/buffer ATPMS $\left(25^{\circ} \mathrm{C}\right)$, after resting at $27^{\circ} \mathrm{C}$ for $120 \mathrm{~min}$

Homogenization OFM

\begin{tabular}{|c|c|c|c|c|c|}
\hline Experiment & Time (min) & Temperature $\left({ }^{\circ} \mathrm{C}\right)$ & $V_{R}$ & $K_{\mathrm{G} 6 \mathrm{PD}}$ & $K_{A L}$ \\
\hline 1 & 15 & 45.0 & $0.66 \pm 0.03$ & $0.31 \pm 0.02$ & $11.8 \pm 0.5$ \\
\hline 2 & 15 & 25.0 & $0.65 \pm 0.04$ & $0.30 \pm 0.03$ & $12.0 \pm 0.7$ \\
\hline 3 & 45 & 25.0 & $0.66 \pm 0.04$ & $0.30 \pm 0.03$ & $12.0 \pm 0.7$ \\
\hline
\end{tabular}


Table 4. Effect of different homogenization conditions at oscillatory flow mixing ((a) constant amplitude; (b) constant frequency) on the volumetric ratio of the phases $\left(V_{R}\right)$, and on the partition coefficients of G6PD and of the affinity ligand ( $K_{\mathrm{GGPD}}$ and $K_{A L}$, respectively) in $3 \%$ wt/wt Triton X-114/buffer ATPMS $\left(25^{\circ} \mathrm{C}\right)$, after resting at $27^{\circ} \mathrm{C}$ for $120 \mathrm{~min}$

\begin{tabular}{|c|c|c|c|c|c|}
\hline \multirow[b]{2}{*}{ Experiment } & \multicolumn{2}{|c|}{ Homogenization OFM } & \multirow[b]{2}{*}{$V_{R}$} & \multirow[b]{2}{*}{$K_{\mathrm{G} 6 \mathrm{PD}}$} & \multirow[b]{2}{*}{$K_{A L}$} \\
\hline & Frequency $\left(\mathrm{s}^{-1}\right)$ & Amplitude $(\mathrm{mm})$ & & & \\
\hline (a) 1 & 25.5 & 3.0 & $0.62 \pm 0.02$ & $0.30 \pm 0.03$ & $12.0 \pm 0.6$ \\
\hline 2 & 12.5 & 3.0 & $0.60 \pm 0.02$ & $0.31 \pm 0.02$ & $12.0 \pm 0.6$ \\
\hline 3 & 2.0 & 3.0 & $0.66 \pm 0.03$ & $0.28 \pm 0.02$ & $12.2 \pm 0.4$ \\
\hline (b) 4 & 12.5 & 0.5 & $0.66 \pm 0.03$ & $0.30 \pm 0.03$ & $12.0 \pm 0.5$ \\
\hline 5 & 12.5 & 1.5 & $0.65 \pm 0.04$ & $0.30 \pm 0.03$ & $12.0 \pm 0.5$ \\
\hline 6 & 12.5 & 3.0 & $0.60 \pm 0.04$ & $0.31 \pm 0.02$ & $12.0 \pm 0.5$ \\
\hline
\end{tabular}

Table 5. Effect of different rest temperatures in different systems of homogenization (simple rotation, $8 \mathrm{rpm} / 15 \mathrm{~min}$; or oscillatory flow mixing, $25.5 \mathrm{~s}^{-1} / 3.0 \mathrm{~mm} / 15 \mathrm{~min}$ ) on the volumetric ratio of the phases $\left(V_{R}\right)$, and on the partition coefficients of G6PD and of the affinity ligand (KG6PD and $K_{A L}$, respectively) in $3 \% \mathrm{wt} / \mathrm{wt}$ Triton $\mathrm{X}-114 /$ buffer ATPMS $\left(25^{\circ} \mathrm{C}\right)$, after resting for $120 \mathrm{~min}$

\begin{tabular}{|lclrrr|} 
Experiment & Rest temperature $\left({ }^{\circ} \mathrm{C}\right)$ & Homogenization system & \multicolumn{1}{c}{$V_{R}$} & \multicolumn{1}{c}{$K_{\mathrm{G} 6 \mathrm{PD}}$} \\
\hline 1 & 27.0 & rotation & $0.60 \pm 0.04$ & $0.26 \pm 0.02$ & $12.2 \pm 0.5$ \\
2 & & oscillatory & $0.62 \pm 0.03$ & $0.30 \pm 0.02$ & $12.0 \pm 0.5$ \\
3 & 29.0 & rotation & $0.37 \pm 0.02$ & $0.27 \pm 0.01$ & $9.6 \pm 0.4$ \\
4 & & oscillatory & $0.36 \pm 0.03$ & $0.26 \pm 0.02$ & $10.9 \pm 0.5$ \\
5 & 32.0 & rotation & $0.30 \pm 0.04$ & $0.10 \pm 0.06$ & $7.0 \pm 0.4$ \\
6 & & oscillatory & $0.30 \pm 0.05$ & $0.20 \pm 0.04$ & $7.8 \pm 0.3$ \\
\hline
\end{tabular}

enough to improve, through affinity interactions, the partitioning selectivity of the target enzyme. In the results obtained (Table 4), experiments marked with (a) are those performed at a constant value of amplitude and those marked with (b) are those performed at a constant value of frequency. Again, there was no significant difference between the results, thus answering any doubt about the possibility of the interaction between the biomolecules (in this case G6PD enzyme) and the ligand being related to the partition performance.

The OFR potentially has a number of niche applications but we are most interested in its ability to generate good mixing conditions in reactors of greatly reduced length-to-diameter ratio and in the possibility of an easy scale-up process. In this work, it was not possible to observe a supplementary contribution of the micro-reactor in liquid-liquid extraction, but it was proven that the micro-reactor, with all the advantages related to the homogenization control (temperature, oscillation intensity, screening factor, and scale-up), proceeded in a similar way to the traditional rotator used in laboratory ATPMS experiments. Thus, it is expected that through a better mutual understanding of the interactions between biomolecules and affinity ligand in ATPMS, or simply of the liquid-liquid extraction system and oscillatory conditions, new partnerships can be established contributing to create new procedures and industrial applications in ATPMS.

An alternative investigation was made at rest temperature and its interference in the partition coefficient of the G6PD and affinity ligand. The partition coefficient of the ligand $\left(K_{A L}\right)$ decreases with increasing temperature, according to Table 5. In other words, increasing the temperature leads to high micelles concentration in the micelle-rich phase and, consequently, to a decreased partition of the ligands to the micelle-rich phase. The partition coefficients of Cibacron Blue obtained in the TX-114 system at $27.0^{\circ} \mathrm{C}$ were higher than those obtained at 29.0 and $32.0^{\circ} \mathrm{C}$. In agreement with the results obtained and as shown in Table 5, the G6PD partition coefficient also decreased at higher rest temperatures.

\section{CONCLUSIONS}

The development of biotechnological techniques and modern methods for the separation and purification of bioproducts has been of paramount importance for many of the advances registered in the biotechnological industry. This paper details observations in this research field using a novel micro-reactor, operated under oscillatory flow mixing, with an aqueous twophase micellar system. Based on the results obtained in this work, no improvements were observed in the partitioning selectivity of glucose 6-phospahe dehydrogenase (G6PD) using aqueous twophase micelar systems (ATPMS) in oscillatory flow mixing (OFM) when compared with those obtained in a simple rotation agitator. These results suggest that the micro-OFR technology (operated under controllable conditions of temperature, mixing, and mass transfer) can give good performance when used in ATPMS. The results indicate the potential of using the OFR as a promising and new alternative for the purification or pre-concentration of bioproducts. On the other hand, some results suggest interference of the rest temperature on G6PD partition during the partitioning equilibrium stage in ATPMS in the presence of an affinity ligand (Cibacron Blue).

\section{ACKNOWLEDGEMENTS}

The authors acknowledge the financial support from FCT (Fundação para a Ciência e Tecnologia/Portugal, SFRH/BPD/ 26108/2005), as well as from FAPESP (Fundação de Amparo à Pesquisa do Estado de São Paulo/Brasil), CNPq (Conselho Nacional 
de Desenvolvimento Científico e Tecnológico/Brasil), and CAPES (Coordenação para Aperfeiçoamento do Ensino Superior/ Brasil).

\section{REFERENCES}

1 Rito-Palomares M, Bioseparation, the limiting step in bioprocess development. J Chem Technol Biotechnol 83:115-116 (2008).

2 Mazzola PG, Lopes AM, Hasmann FA, Jozala AF, Penna TCV, Magalhaes $\mathrm{PO}$, et al, Liquid-liquid extraction of biomolecules: an overview and update of the main techniques. J Chem Technol Biotechnol 83:143-157 (2008).

3 Hasmann FA, Cortez DV, Gurpilhares DB, Santos VC, Roberto IC and Pessoa-Jr A, Continuous counter-current purification of glucose6-phosphate dehydrogenase using liquid-liquid extraction by reverse micelles. Biochem Eng J 34:236-241 (2007).

4 Kilikian BV, Bastazin MR, Minami NM, Gonçalves EMR and Pessoa-Jr A, Liquid-liquid extraction by reverse micelles in biotechnological processes. Braz J Chem Eng 17:29-38 (2000).

5 Liu C, Kamei DT, King JA, Wang DIC and Blankschtein D, Separation of proteins and viruses using two-aqueous micellar systems. J Chromatogr B 711:127-138 (1998).

6 Lee CK and Su WD, Nonionic surfactant-mediated affinity cloud point extraction of vancomycin. Sep Sci Technol 34:3267-3277 (1999).

7 Van Roosmalen D, Dohmen-Speelmans MPJ, Dietz CHJT, Van Den Broeke LJP, Van DerWielen, LAM and Keurentjes JTF, Bioseparations in aqueous micellar systems based on excluded-volume interactions. Food Bioprod Process 84:51 - 58 (2006).

8 Lam H, Kavoosi M, Haynes CA, Wang DIC and Blankschtein D, Affinityenhanced protein partitioning in decyl $\beta$-D-glucopyranoside twophase aqueous micellar systems. Biotechnol Bioeng 89:381-392 (2005).

9 Rangel-Yagui CO, Lam H, Kamei DT, Wang DIC, Pessoa-Jr A and Blankschtein D, Glucose-6-phosphate dehydrogenase partitioning in two-phase aqueous mixed (nonionic/cationic) micellar systems. Biotechnol Bioeng 82:445-456 (2003).

10 Lopes AM, Rangel-Yagui CO and Pessoa-Jr A, Can affinity interactions influence the partitioning of glucose-6-phosphate dehydrogenase in two-phase aqueous micellar systems. Quim Nova 31:998-1003 (2008).

11 Dias R, Mel'nikov S, Lindman B and Miguel MG, DNAphase behavior in the presence of oppositely charged surfactants. Langmuir 16:9577-9583 (2000).

12 Everberg $\mathrm{H}$, Leiding $\mathrm{T}$, Schioth $\mathrm{A}$, Tjerneld $\mathrm{F}$ and Gustavsson $\mathrm{N}$, Efficient and non-denaturing membrane solubilization combined with enrichment of membrane protein complexes by detergent/polymer aqueous two-phase partitioning for proteome analysis. J Chromatogr A 1122:35-46 (2006).

13 Mazzola PG, Lam H, Kavoosi M, Haynes CA, Pessoa-Jr A, VessoniPenna TC, et al, Affinity-tagged green fluorescent protein (GFP) extraction from a clarified $E$. coli cell lysate using a two-phase aqueous micellar system. Biotechnol Bioeng 93:998-1004 (2006).

14 Simon L, Aqueous two-phase extraction - a case study in process analysis and control. AIChE Annual Meeting - Cincinnati, $\mathrm{OH} 237$ e (2005).

15 Porto ALF, Sarubbo LA, Moreira KA, Melo HJF, Lima-Filho JL, CamposTakaki GM, et al, Recovery of ascorbic oxidoreductase from crude extract with an aqueous two-phase system in a perforated rotating disc contactor. Braz Arch Biol Technol 47:821 -826 (2004).

16 Brunold CR, Hunns JCB, Mackley MR and Thompson JW, Experimental observations on flow patterns and energy-losses for oscillatory flow in ducts containing sharp edges. Chem Eng Sci 44:1227-1244 (1989).

17 Dickens AW, Mackley MR and Williams HR, Experimental residence time distribution measurements for unsteady-flow in baffled tubes. Chem Eng Sci 44:1471 - 1479 (1989).
18 Mackley MR and Ni X, Mixing and dispersion in a baffled tube for steady laminar and pulsatile flow. Chem Eng Sci 46:3139-3151 (1991).

19 Mackley MR and Ni X, Experimental fluid dispersion measurements in periodic baffled tube arrays. Chem Eng Sci 48:3293-3305 (1993).

$20 \mathrm{Ni} \mathrm{X}$, Jian $\mathrm{H}$ and Fitch AW, Computational fluid dynamic modelling of flow patterns in an oscillatory baffled column. Chem Eng Sci 57:2849-2862 (2002).

21 Ni XW, Murray KR, Zhang YM, Bennett D and Howes T, Polymer product engineering utilizing oscillatory baffled reactors. Powder Technol 124:281-286 (2002).

22 Harvey AP, Mackley MR and Seliger T, Process intensification of biodiesel production using a continuous oscillatory flow reactor. J Chem Technol Biotechnol 78:338-341 (2003).

23 Gao S, Ni X, Cumming RH, Greated CA and Norman P, Experimental investigation of bentonite flocculation in a batch oscillatory baffled column. Sep Sci Technol 33:2143-2157 (1998).

24 Bergmeyer HU, Bergmeyer J and Grassl M, Methods of Enzymatic Analysis: Samples, Reagents, Assessment of Results. Verlag Chemie, Weinheim (1983)

25 Whitaker JR, Enzymes in analytical chemistry, in Food Enzymology, ed by Fox PF. Elsevier Applied Science, New York, pp. $287-308$ (1991).

26 Godfrey $T$ and West $S$, Introduction to industrial enzymology, in Industrial Enzymology, ed by Godfrey T. Macmillan Press, London pp. 1 -8 (2001).

27 Silva DP, Pessoa-Jr A, Roberto IC and Vitolo M, Effect of kLa on the production of glucose-6-phosphate dehydrogenase from Saccharomyces cerevisiae grown by fermentation process. Appl Biochem Biotechnol 98:205-213 (2002).

28 Nikas YJ, Liu CL, Srivastava T, Abbott NL and Blankschtein D, Protein partitioning in two-phase aqueous nonionic micellar solutions. Macromolecules 25:4794-4806 (1992).

29 Albertsson PA, Partition of Cell Particles and Macromolecules. WileyInterscience, New York (1986).

30 Blankschtein D, Thurston GM and Benedek GB, Phenomenological theory of equilibrium thermodynamic properties and phase separation of micellar solutions. J Chem Phys 85:7268-7288 (1986).

31 Ramelmeier RA, Terstappen GC and Kula MR, The partitioning of cholesterol oxidase in Triton X-114 based aqueous two-phases systems. Bioseparation 2:315-324 (1991).

32 Reis N, Harvey AP, Vicente AA, Teixeira JA and Mackley MR, Fluid mechanics and design aspects of a novel oscillatory flow mesoreactor. Chem Eng Res Des 83:357-371 (2005).

33 Reis N, Gonçalves CN, Vicente AA and Teixeira JA, Proof-of-concept of a novel micro-bioreactor for fast development of industrial bioprocesses. Biotechnol Bioeng 95:744-753 (2006).

34 Liu CL, Nikas YJ and Blankschtein D, Novel bioseparations using twophase aqueous micellar systems. Biotechnol Bioeng 52:185-192 (1996).

35 Saitoh T, Hinze WL and Inze WL, Use of surfactant-mediated phase separation (cloud point extraction) with affinity ligands for the extraction of hydrophilic proteins. Talanta 42:119-127 (1995).

36 Champluvier B and Kula MR, Dye-ligand membranes as selective adsorbents for rapid purification of enzymes: a case study. Biotechnol Bioeng 40:33-40 (1992).

37 Chang YK, MCcreath GE and Chase HA, Development of an expanded bed technique for an affinity purification of G6PDH from unclarified yeast cell homogenates. Biotechnol Bioeng 48:355-366 (1995).

38 Harvey AP, Mackley MR and Stonestreet P,Operation and optimization of an oscillatory flow continuous reactor. Ind Eng Chem Res 40:5371-5377 (2001).

39 Reis N, Novel oscillatory flow reactors for biotechnological applications. PhD thesis, University of Minho, Braga, Portugal, pp. 263 (2006). 